\title{
Eosinophilic Granuloma
}

National Cancer Institute

\section{Source}

National Cancer Institute. Eosinophilic Granuloma. NCI Thesaurus. Code C3016.

A clinical variant of Langerhans cell histiocytosis characterized by unifocal involvement of a bone (most often), skin, or lung. Patients are usually older children or adults usually presenting with a lytic bone lesion. The etiology is unknown. Morphologically, eosinophilic granuloma is characterized by the presence of Langerhans cells in a characteristic milieu which includes histiocytes, eosinophils, neutrophils, and small, mature lymphocytes. 